\title{
Research and Analysis of UNESCO's MIL Assessment Framework
}

\author{
Yong Li* \\ College of Computer Sci. and Eng. , \\ Changchun University of Technology \\ Changchun, Jilin, P.R.China \\ liyong@mail.ccut.edu.cn
}

\author{
Xiaohu Wang \\ College of Computer Sci. and Eng. , \\ Changchun University of Technology \\ Changchun, Jilin, P.R.China \\ wangxiaohu@mail.ccut.edu.cn
}

\author{
Chun $\mathrm{Yu}$ \\ Dept. of Basic Teaching and Research \\ Armored Academy of Technology \\ Changchun, Jilin, P.R.China \\ 478298878@qq.com
}

\begin{abstract}
UNESCO published Global Media and Information Literacy Assessment Framework (hereinafter referred to as MIL Assessment Framework), striving to offer practical guidance for tools and methods to all member states for carrying out a comprehensive assessment on media and information literacy. This paper makes a preliminary analysis of MIL Assessment Framework, and on this basis shows some guiding significance of MIL Assessment Framework for Chinese media and information literacy assessment and improvement of media and information literacy.
\end{abstract}

Keywords-Media and Information Literacy; Media and Information Literacy Assessment; Assessment Framework

\section{INTRODUCTION}

On December 11, 2013, United Nations Educational, Scientific, and Cultural Organization (UNESCO) published Global Media and Information Literacy Assessment Framework which offered guidance for practical tools and methods to all member states to carry out a comprehensive assessment on media and information environment. The framework was aimed at monitoring media and information literacy (hereinafter referred to as MIL) levels from national, regional and individual levels, especially teachers in fields of service and training, and on this basis deploying practical domestic condition based, action-oriented programs and strategic decisions. [1]

In recent years, rapid development of information and communication technology (ICT) has promoted large-scale clustering, processing and presentation of media and information, and has constructed a globally shared virtual world. While offering new forms of free expression, integration into society, economy and culture, ICT also widened digital divide and brought new challenges. Since its establishment, UNESCO has been devoted to improving territorial inequality in information, media and education, and promoting free access

This paper is one of the phased achievements of 2015 Jilin Education Science "12th Five-Year" Key Project: Investigation and Countermeasures on the present situation of University Teachers' Information Literacy based on MIL Assessment Framework in Jilin (No.ZD15043).

*Corresponding author. to acquisition and application of information and knowledge across the world.

To effectively accommodate media and information literacy into global education plan and cultivate new citizens of this information era, UNESCO has adopted a series of initiatives in recent years, which fully reflected its close attention and keen emphasis on media and information literacy.

\section{CONCEPT OF INFORMATION LITERACY}

"Literacy" is a diversified, situational and dynamic concept. Since human stepped into the 21 st Century, all nations in the world entered into an information society from an industrial one in succession. The new-type society requires citizens to equip themselves with new capabilities to adapt to the everchanging environment. With sustaining influence and impact of information, media, communication technology and digital world, the concept of "literacy" has undergone development in the past decade. Boundaries between different concepts are gradually becoming indistinct and several concepts are moving toward a trend of recombination step by step.

The concept of "media literacy" stems from 1930s and has been rapidly developed in recent 20 years. It can date back to the use of screen materials. In Britain, media literacy is defined as a capability to acquire, understand and create communication under multiple situations; [2]In North America, media literacy is regarded as a combination of a series of communication capabilities, including capabilities to acquire, analyze and express information of various forms. The information can be papery or non-papery. [3][4]Despite of different expressions of the media literacy concept, they all focus on critically processing media information, improving capabilities to acquire, understand, analyze, use and create media products. The concept of "information literacy stems from the skill of book retrieval". [5]Around 1974, information literacy emphasized the use of multiple tools, formats and channels to acquire information, and the importance of assessment, creation and sharing of information and knowledge. 
A research group of US National Forum on Information Literacy believes that information literacy is a capability to acquire, evaluate and use information from different sources. They proposed a series of measurement indexes on this basis. A research group from University of Calgary considers that information literacy is a capability to realize his needs of information, and know how to acquire, evaluate, synthesize and communicate. [6]In an article of UNESCO entitled Towards Information Literacy Indicators, Catts and Lau argue that individuals with information literacy should be equipped with the following capabilities: (1) recognize their information needs; (2) acquire and evaluate the quality of the information; (3) store and retrieve information; (4) make effective and ethical use of information; (5) apply information to create and communicate knowledge. [7]'Information literacy" usually means a capability to effectively and critically acquire and evaluate information of different formats (especially digital format) from a series of sources and to create new knowledge in virtue of a series of tools and resources (especially digital technology) on this basis. For the concept itself, digital literacy and media literacy are highly close to each other, which is mainly embodied in helping users communicate and cooperate with each other safely and morally.

Media literacy, information literacy and digital literacy have different academic origins and research categories. Media literacy roots in studies of media and people, focuses on media contents, media industry, and social influence and, has strong social connotation; information literacy stems from library science and information science, focuses on creation and use of knowledge and sufficient awareness of learning process (information storage, processing and use); digital literacy roots in computer science and informatics. Even if information literacy focuses on how to use different technical tools to manage information of different formats and forms; media literacy focuses on acquisition and development of media; digital literacy concentrates on capabilities to use digital equipment and software, and openness and transparency of information communication technology.

In recent years, with gradual and thorough application of information technology, concepts such as media literacy, information literacy and digital literacy are showing a development trend of increasing integration. On the one hand, mass media and information communication technology are irreversibly affecting daily life, learning and work of people. People are in urgent need of multiple literacy technologies and capabilities under new technology environment. Simplex information literacy or media literacy is not enough to present individuals, capabilities to respond and use media and information. [8][9] On the other hand, technological integration blurred boundaries between different literacy. Here, rapid development and thorough application of digital technology are the main reason for the integration of media literacy and information literacy. In $1990 \mathrm{~s}$, Koelsch considered that computer technology extends connotation of media literacy to information literacy. [10][11]Experts of information literacy have realized the necessity to connect with the media circle and that critical analysis of retrieved information should be given more attention. In termsd of media literacy, facing mass information in such a digital era, employees are also profoundly aware of the importance of improving information literacy and proficiently searching, evaluating and using information.

The template is used to format your paper and style the text. All margins, column widths, line spaces, and text fonts are prescribed; please do not alter them. You may note peculiarities. For example, the head margin in this template measures proportionately more than is customary. This measurement and others are deliberate, using specifications that anticipate your paper as one part of the entire proceedings, and not as an independent document. Please do not revise any of the current designations.

\section{ANALYSIS ON GLOBAL MEDIA AND INFORMATION LITERACY ASSESSMENT FRAMEWORK}

Global Media and Information Literacy Assessment Framework published by UNESCO strives to offer practical tools, methods and guidance for all member states to carry out a comprehensive assessment on media and information literacy. MIL Assessment Framework consists of three parts:

First, theoretical basis. Transition of "literacy" concept; relation and integration of different literacies, and their effect on the society; concept and theoretical basis of MIL; potential benefits of MIL for the society, communities and individuals; conditions for MIL to develop; theoretical basis for nations to implement MIL assessment.

Second, details of assessment framework. Assessment objects, purposes and structures of MIL. The first layer is degree of readiness of the nation. Assess the readiness degree of the nation to improve measures related with MIL; the second layer is an assessment on individuals ' MIL capability, especially focusing on capabilities of teachers in fields of service and training.

Third, implementation of the assessment. Offer guidance for methods and feasible suggestions to implement MIL assessment; propose further countermeasures and solutions according to the assessment results; offer various practical assessment tools for nations and individuals.

MIL Assessment Framework consists of two layers: degree of readiness of the nation, MIL capability:

\section{A. MIL readiness degree of the nation}

"MIL readiness degree of the nation" describes readiness degree of the nation to adopt related measures to enhance MIL level. Assessment index of readiness degree of the nation in MIL Assessment Framework contains the following five aspects: media and information literacy in education, media and information literacy policy, media and information supply, media and information access and use and civil society.

\section{1) Media and information literacy in education}

This assessment index mainly investigates the degree that the nation accommodates MIL education into preschool education, basic information, teacher training and higher education and the supporting level of MIL for different educational levels. Main investigation projects include: i. General situation of national education; ii. Policies for teachers; iii. Media and information literacy in education, for example, 
curriculums related to media and information literacy, policies, plans, laws or regulation mechanisms promoting ICT implementation and educational integration, training policies for integration of ICT and education, different type(s) of MIL training to be offered to teachers, if there is MIL projects contained in regular curriculums of different stages of school study, or if libraries organize regular MIL training.

\section{2) Media and information literacy policy}

MIL policies of the nation determine success of MIL related measures. Investigations on MIL policies contribute to understanding media and information literacy environments in different nations and comparing them with each other. This investigation contains two parts: i. Media regulatory institutes or organizations of the nation; ii. Related laws and regulations.

\section{3) Media and information supply}

To some extent, the quality of media and information is under the influence of national regulatory mechanism. Usability of media and resources is a key factor concerning immediate environment of citizens. Therefore, the investigation contains two aspects: i. Current status of accessible data and resources; ii. General situation of media and information of the nation, such as coverage rate of newspapers, broadcasts, televisions, phones, web service, quantity of libraries, museums and movie theatres, etc.,

\section{4) Media and information acquisition and application}

This is embodied through information acquisition, communication technology and other related indexes, including coverage rate of mobile telephone and broadband, proportion of families owning broadcasts or televisions, circulation amount of printed newspapers, quantity and proportion of computers owned by individuals or families, quantity of IT labs in schools, and energization rate in families. The higher the ICT usability is, the higher the need and opportunity that citizens efficiently use information resources and acquire MIL capabilities will be.

\section{5) Civil society}

This concerns various stakeholders and involves investigations on non-governmental organizations, community organizations, academic network, professional associations, private entities, and other key stakeholders undertaking and supporting media and information literacy work. They cooperate with other organizations, offer MIL training to citizens, develop new products and services, advocate, promote and encourage citizens to work on social activities.

Readiness degree of the nation as described in MIL Assessment Framework consists of the following three grades:

i. Highly favorable environment. Five indexes related with MIL environment are all included, and receive good development and support on the national level;

ii. Relatively favorable environment. Most of indexes are included, and receive development and support on the national level while parts of the indexes still need to be enhanced;

iii. Less favorable/adverse environment. Most of MIL indexes need to be enhanced while parts of them are missing.
Five aspects and three levels of MIL readiness degree of the nation are constituted as Picture 1.

\section{B. Competency of MIL and its performance level}

The second layer of MIL Assessment Framework adopts MIL competency matrix to describe competencies and performance of citizens in MIL. MIL competency matrix contains five aspects: MIL component, MIL subject matter, competency, performance criteria, and proficiency level. In the MIL competency matrix, MIL factors include acquisition, assessment and creation as described in Picture 2.



Fig. 1. MIL country readiness model[1]

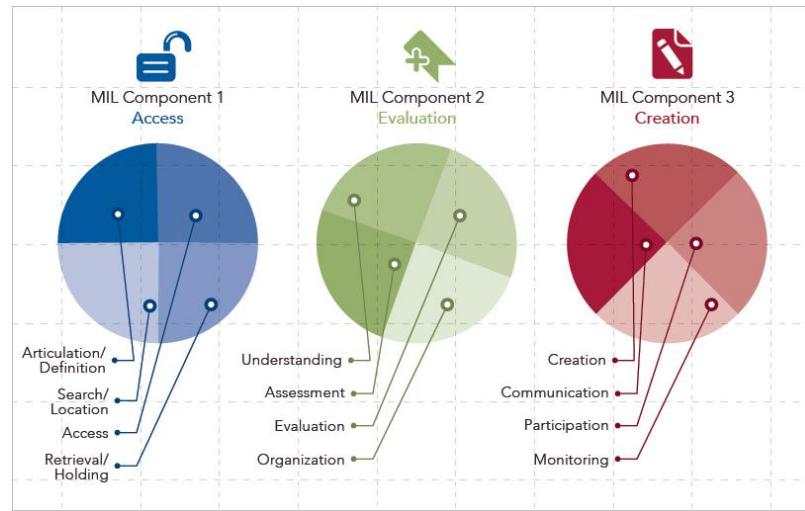

Fig. 2. MIL broad components associated to the MIL subject matters[1]

\section{MIL Component 1: acquisition}

"Acquisition" means competencies to use appropriate technology to visit, retrieve and store information and media contents. It includes competencies to specify information, media contents and knowledge needs, to identify information and media contents of various sources and formats (papery format, voice frequency, image and digital format), and to retrieve information from digital or physical libraries, museums, personal documents or other sources.

"Acquisition" factor is refined into four "MIL second level indexes", matching with four competencies and thirty-six related performance criteria.

\section{MIL Component 2: assessment}

"Assessment" means competencies to understand, critically analyze and assess information, media contents, media, and work and functions of information organizations in the context 
of universal human rights and basic freedom, including comparing truths, distinguishing truths in opinions, detecting opportunities, identifying important ideologies and values, questioning how social, economic, political, professional persons and technical forces shape media and information contents, and assessing information quality (accuracy, correlation, circulation time, reliability and integrity).

In an era of information explosion, individuals firstly need to grasp technology and skills to organize, extract, and synthesize media and information; secondly, understanding connotations of nature, functions and operations of media organizations, media professionals and information providers is crucial for understanding how to reconstruct information and media news; thirdly, in a more extensive context, specifying functions of media and information plays a highly important role in promotion of freedom of expression, freedom of information and information acquisition, and also contributes to understanding relations between MIL, civic rights, democracy and good governance and their influences; finally, individuals with media and information literacy are capable of understanding economic, social and political forces and monitoring influences of media companies, information providers and public institutions.

"Assessment" factor is refined into four "MIL second level indexes", matching with 4 competencies and forty-two related performance criteria.

\section{MIL Component 3: creation}

"Creation" means competencies to grasp information and media contents, build new knowledge and make effective communication with others, including morally and effectively using information and media contents, being equipped with basic knowledge (such as knowledge of intellectual property). To be equipped with media and information literacy not only asks for skills of analysis and production, but also requires knowledge related with media and information, as well as attitude and values to morally use media, information and ICT. Citizens with MIL are able to participate in and supervise process of democratization. Therefore, monitoring of media production, knowledge creation, application, and influence is also a key factor of MIL.

"Creation" factor is refined into four "MIL second level indexes", matching with four competencies and thirty-five related performance criteria.

\section{GUIDING SIGNIFICANCE OF MIL ASSESSMENT FRAMEWORK FOR ENHANCING MIL IN CHINA}

MIL Assessment Framework is a programmatic document originally published by UNESCO, aiming at MIL assessment. This framework offers important guiding significance for Chinese citizens to cultivate and enhance media and information literacy in the information era on multiple levels including macro strategy, implementation strategy and microcosmic operation.

(1) On macro strategy level: apart from a global vision, the situation of the nation should be also taken into consideration to improve MIL education and teaching systems, perfect related laws and regulations of media and information and enhance MIL. According to the experience of the developed nations, it is undoubtedly an effective method to accommodate MIL education into education systems and conduct routine MIL education in schools of different levels and categories. In fact, Department of Education and Science of Britain had accommodated media literacy education into official education systems as early as 1989, and National Administrative Department for Education had been responsible for curriculum development. Nevertheless, theoretically and practically, MIL education in China still faces many problems demanding prompt solutions.

On the one hand, China had issued Information Technology Curriculum Standard for regular senior high schools as early as a decade ago, allowing MIL education during senior high schools to "have rules to follow". Recently, Ministry of Education commenced on modifying the Information Technology Curriculum Standard for Senior High Schools. In recent years, information technology curriculums have been set up in most primary schools and junior high schools in China, however, there has been no Information Technology Curriculum Standard suitable for corresponding learning phases, causing different selections of teaching contents of this curriculum and uneven academic achievements in different schools.

On the other hand, many achievements have been made in theoretical researches on integration of information technology curriculum and other subject curriculums. However, deficiencies still exist in practical application. Therefore, it is urgently needed for China to develop Information Technology Curriculum Standard facing the stage of compulsory education and closely related to MIL, to improve the systems of MIL training and MIL competencies in education departments and institutions of various levels and categories. Related scientific research academies and institutes should focus on special researches on MIL, strengthen strategies for MIL teaching, scientific research development, and regional development, and continuously support and assist in researches and construction of information technology and curriculum integration, and researches on MIL resources and curriculum construction and sharing mechanism. Meanwhile, MIL competency training for citizens should be continuously emphasized on the national level, and libraries and science popularization venues of different levels and categories should play a positive role in enhancing MIL of citizens.

In the MIL Assessment Framework, one of assessment indexes for readiness degree of the nation is MIL-related polities and laws and regulations, which is sufficient to show the importance of policies and laws for MIL improvement. MIL improvement firstly requires related policies, laws and regulations as guarantee. Since 1990s when China officially accessed to internet, it has issued related policies, laws and regulations in succession, however, its attention to media and information literacy has been slightly insufficient. In the next step, it is expected to establish and perfect related media regulatory institutions and self-regulatory organizations on the national level and to further improve related laws, policies and certification systems to guarantee and accelerate the improvement and sustainable development of MIL on the national level. 
(2) On implementation strategy level: pay equal attention to MIL assessment and intervention and give full play to strengths of non-government institutions. One distinguishing feature in MIL Assessment Framework is its strong operability, which offers not only assessment system and specific indexes, but also practical guidance for the assessment process, analysis on assessment results and suggestions based on the results. The framework divides the assessment process into six stages, namely, setting up an assessment group; designing assessment plan; selecting tools and documents; applying tools in the framework to collect data; monitoring MIL readiness degree of the nation and individual competencies on the basis of data analysis; proposing measures to further improve environment, enhance MIL and for other related purposes.

Taking examples of the MIL Assessment Framework here, the picture below is specific situation of MIL of a nation and the grey part shows its level in this field.

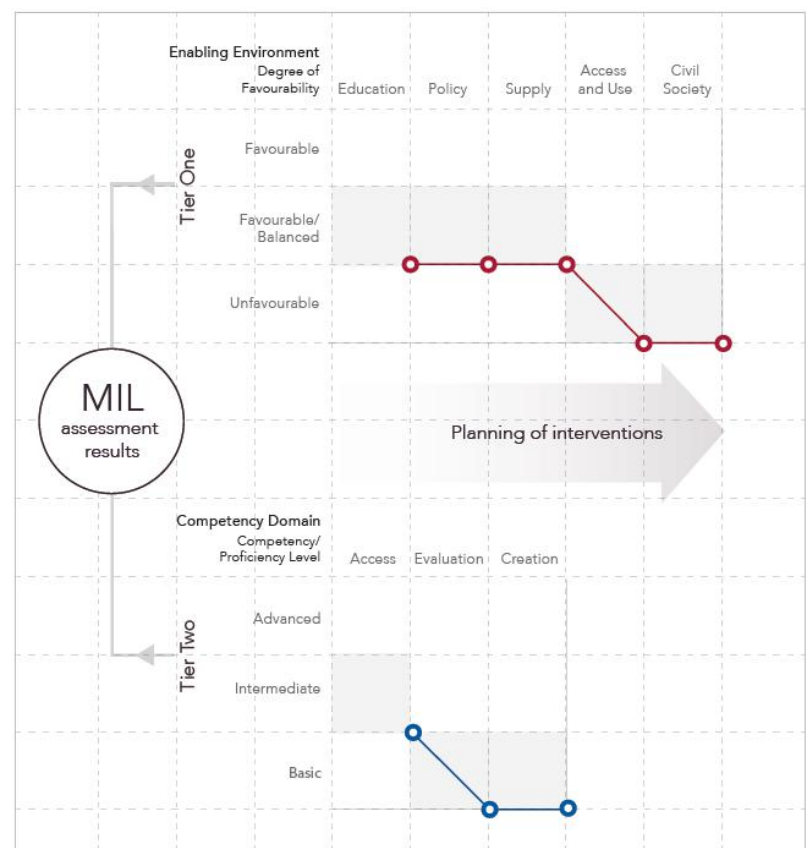

Fig. 3. Proposed analysis of the assessment results and scenarios formulation

According to Picture 3[1], the nation owns relatively favorable environment, however, its citizens have low levels of personal capabilities. Therefore, it should focus on the cultivation of personal capabilities and further improve its MIL environment. Besides, "acquisition-use" and "civil society" should be given special attention. It can be discerned from the analysis of this example that MIL level in China should be also improved based on data of readiness degree and individual capabilities. Intervention measures on two levels and eight dimensionalities should be proposed according to the specific national conditions.

Education of media and information literacy requires not only political promotion but also strengths from nongovernment institutions. The influence of MIL on the society in the assessment framework is as Fig. 4.

The annular in Picture 4 is formed by two curve arrows respectively referring to society and education. In the "society level", policy makers with literacy will promote formation of an active civil society with literacy. In such a society, individuals will responsibly, morally and effectively use information media. "Education level" owns high quality workers and high level labor markets on the basis of "society level", then outputs educators conforming to social needs. Educators summarize practical experience, formulate educational plans and further cultivate well-informed policy makers with high literacy. The entire annular loop is a favorable influence circulation of media and information literacy for the society. Non-government organizations are playing an important role in both of these two curves, especially the effects of education and training organizations in the second curve, which bring direct influences and contributions to planning of education strategies, improvement of teaching process and promotion of personal capabilities.

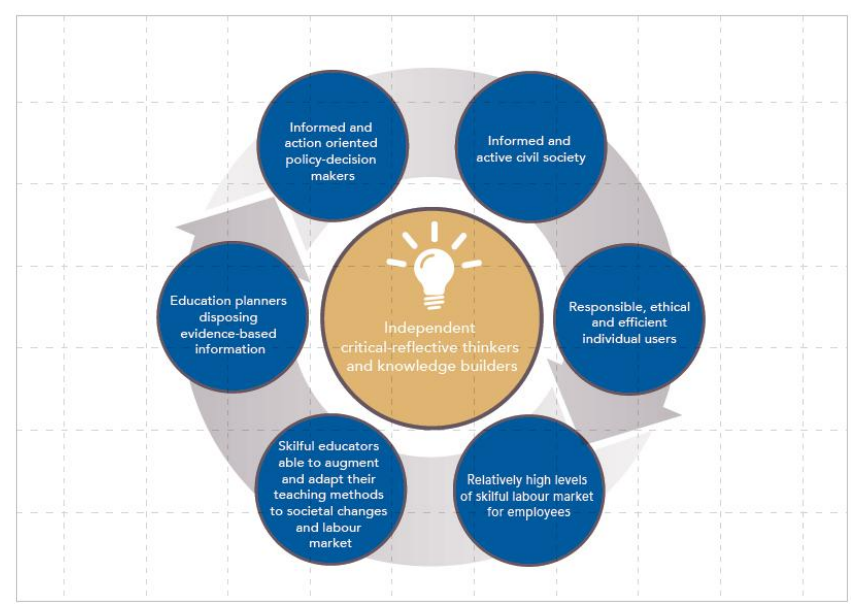

Fig. 4. Direct impact of MIL to society[1]

In recent years, diversified development of education and alternative education consumer demands in China keep a sustainable growth, making non-government education organizations and groups become a new emerging force in the education ecosystem. Non-government education organizations into which the market mechanism is introduced have obvious system advantages compared to state-running education organizations. The former ones not only create a fair, freely selective environment, but also realize an optimized, flexible and efficient allocation of educational recourses. Relevant nongovernmental organizations, such as Chinese Association of Educational Technology (CAET) and professional organizations and institutions of educational technology of provinces, have been annually carrying out teachers ' educational technology achievement exhibitions and information technology capability appraisals of teachers, which motivated teachers' enthusiasm in information technology application and encouraged creative application of information technology in education of different levels and categories. Therefore, development of media and information literacy can give full play to the strengths of non-government organizations, seek supports from such non-government organizations as companies, non-profit entities and social educational institutions, and jointly promote improvement of media and information literacy, under the policies and guidance of the nation. 
(3) On microcosmic operation level: emphasize teacher training, give play to the bridge effect of national and individual MIL.

MIL Assessment Framework describes MIL levels from the national and individual dimensions. China' $\mathrm{s}$ assessment on MIL before has focused on either individuals or organizations and institutions. In fact, simply focusing on the nation or individual level is insufficient to comprehensively and accurately grasp MIL levels. MIL environment, resources, infrastructure and other related factors of the nation will affect MIL levels of individuals and groups, which will show strengths and weaknesses of national MIL environment to a certain extent in return. Teachers as a link between individuals and the nation are of great significance in guiding and training learners, laborers and innovators of the information society, as well as constructing a knowledge society. The relations between different aspects above are showed in Picture 5.

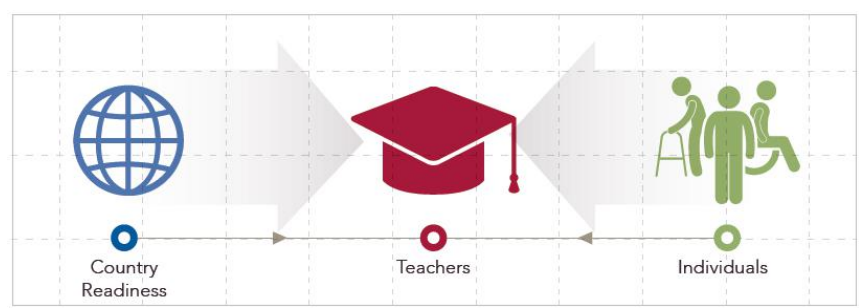

Fig. 5. Role of teachers as gatekeepers and providers of knowledge and skills in society[1]

Therefore, the method of "emphasizing the middle part and promoting both ends" should be adopted to improve and develop MIL. The nation should highly focus on MIL competency cultivation of teachers in schools of different levels and categories, formulate appropriate teacher training policies and professional standards; increase input for hardware equipment to give teachers a quality MIL environment; jointly build tool, teaching material and resource pools; for MIL training of teachers, adjust training plans and curriculum, expand training pattern, develop a dynamic mechanism for training implementation and operation, improve examination certification system, and further improve MIL competencies of teachers. Recently, Ministry of Education issued Standards for Training Curriculum of Information Technology Application
Capabilities of Teachers in Primary and Middle Schools (Trial Implementation), Standards for Information Technology Application Capabilities of Teachers in Primary and Middle Schools (Trial Implementation), Enhancement Project of Information Technology Application Capabilities of Teachers in Primary and Middle Schools and audio visual education centers of different levels have taken the lead for construction and application promotion of teaching resource pool project of primary and middle schools, which have largely and effectively promoted MIL improvement.

\section{REFERENCES}

[1] UNESCO, Global media and information literacy assessment framework: country readiness and competencies, http://www.unesco.org/new/en/ communication-and-information/resources/publications-andcommunication-materials/publications/full-list/global-media-andinformation-literacy-assessment-framework/, 2013.

[2] What is Media Education?, Media Literacy Week, www.medialiteracyweek.ca/ en/101_whatis.htm, 2010.

[3] NAMLE, Media Literacy Defined, National Association for Media Literacy Education, http://namle.net/publications publications/medialiteracy-definitions, 2010.

[4] Alice Y. L. Lee, Media Education: Definitions, Approaches and Development around the Globe, New Horizons in Education, vol. 58(3), pp. 1-13, 2010.

[5] Wang Fan, Zhang Shuyu,Analysis of Media Literacy and Information Literacy From the Perspective of Education, E-education Research, vol. 03, pp. 35-39,2007.In Chinese

[6] Moeller S., Joseph A. , Lau J. \& Carbo T. , Towards Media and Information Literacy indicators, Background Document of the Expert meeting UNESCO, 2011

[7] Catts R. \& Lau J. , Towards Information Literacy Indicators, http://unesdoc.unesco.org/images/0015/001587/158723e.pdf, 2013.

[8] Buckingham D. , Digital Media Literacy: rethinking media education in the age of the Internet, Research in Comparative and International Education, vol. 2(1), pp. 43-55, 2007.

[9] Westby C. , Multi-literacies: The changing world of communication , Topics in Language Disorders, vol. 30(1), pp. 64-71, 2010.

[10] Alice Y. L. Lee, Infomedia literacy: An educational basic for young people in the new information age, Information, Communication \& Society, vol. 2(2), pp. 134-155, 1999.

[11] Koelsch F. , The Info-media Revolution: How it is Changing our World and our Life, McGraw-Hill Ryerson, 1995. 